\title{
Superconducting Gold Alloys
}

\author{
A REVIEW OF THE STATE OF THE ART
}

\section{H.R. Khan}

Forschungsinstitute für Edelmetalle und Metallchemie, D-7070 Schwäbisch Gmünd, Federal Republic of Germany

\begin{abstract}
Although the discovery of a gold alloy with a superconducting state at relatively high temperature would be significant and exciting, it has been a feature of the past decade that technology has advanced to the stage of producing applications for gold and otber alloys which achieve superconductivity at low critical temperatures. A significant research effort bas gone into the search for superconducting gold alloys, study of their properties, and applications for them.
\end{abstract}

In 1975 the author and Ch. J. Raub reviewed the field of superconductivity of gold alloys for this journal (1). At that time it was concluded that although no intermetallic compound of gold had yet been found to exhibit superconductivity at temperatures that would make it industrially useful, the investigation of gold compounds had assisted solid state physicists in their understanding of the phenomenon of superconductivity. It must be borne in mind, of course, that in the mid-1970's 'industrially useful' implied a critical temperature $\left(T_{c}\right)$ of greater than about $20 \mathrm{~K}$. The technological and engineering advances which allow ready application of alloys with very much lower $\mathrm{T}_{\mathrm{c}}$ values were still at that time on the drawing board.

In the review of the state of the art of superconductivity in gold alloys which follows, some material from the author's earlier review in this journal is included and more recent work is discussed in detail. This approach has been selected in view of the changing parameters of technology which are allowing practical consideration of gold alloys which become superconducting at levels of temperatures too low to have been envisaged a decade ago, and in order to present a more complete and comprehensive review.

\section{General Superconducting Behaviour of Gold}

Gold belongs to a group of elements in the periodic system which do not become superconductors even down to the lowest available temperature, although most of the elements are superconducting under normal conditions or high pressures. Some solid solutions and intermetallic compounds of gold with the transition metals show peculiar superconducting behaviour. In general gold lowers the superconducting transition temperature $\left(T_{c}\right)$ of the host transition metal in solid solutions, whereas an enhancement of $T_{c}$ is observed for some intermetallic compounds. Study of a gold-lanthanum alloy led to the discovery of metallic glass superconductors. These glassy superconductors are of great interest because of their superior mechanical and superconducting properties, and the investigations of the superconducting behaviour of gold-containing intermetallic compounds, solid solutions and metallic glasses have enhanced our knowledge of the electronic structure of materials. At the same time some superconducting gold alloys are useful as low temperature reference materials, and as electrode and counter electrode materials in Metal/Oxide/Metal sandwich systems (Josephson junctions).
After the discovery of superconductivity in mercury by Kammerlingh-Onnes in 1908 following his success in liquifying helium, the first superconducting intermetallic compound discovered by de $\mathrm{Haas}$ in 1929 , was the C15-type phase $\mathrm{Au}_{2} \mathrm{Bi}$. Since then most of the elements have been shown to become superconductors under normal conditions or under high pressures. Figure 1 shows the distribution of superconducting elements in the periodic system.

\section{Present Understanding of Superconductivity}

The author discussed briefly in his earlier review (1) theoretical developments in the understanding of superconductivity at that time, and in particular why superconductivity occurred in elements which were poor metallic conductors rather easier than in those which exhibited good conductivity at room temperature.

Thus in relating critical temperatures to other solid state properties it was found that the parameter of greatest importance for the critical temperature was the electronic structure of the material giving a high electron density of states at the Fermi level, the most favourable being the $A-15$ or $\beta$-W structure. The empirical rule discovered by B.T. Matthias which predicted that alloys with average numbers of valence electrons per atom on the lower side of valences 5 and 7 would have high critical temperatures was an important step forward, and the experimental confirmation of the Fröhlich equation describing the inverse proportionality of the critical temperature to the square root of the atomic mass

$$
\mathrm{T}_{c} \alpha \mathrm{M}^{-1 / 2}
$$

led to the discovery that superconductivity is caused by a kind of electron-lattice interaction.

Understanding of superconductivity is largely based on the Bardeen, Cooper and Schrieffer (BCS) model, and its subsequent modifications, which showed that in the superconducting state condensation of pairs of conduction electrons, bonded by virtual phonons, into a lower energy state occurs (2). The acceptability of this model was in no small way due to the manner in which it readily explained the observed trend that superconductivity is more readily achievable in pooter metallic conductors than in good ones.

In this model the critical temperature was related to the Debye temperature $\theta_{D}$, the electron density of states $N(O)$ and the electron-phonon interaction parameter $V$ by:

GoldBull., 1984, 17, (3) 


\begin{tabular}{|c|c|c|c|c|c|c|c|c|c|c|c|c|}
\hline & \\
\hline
\end{tabular}

\begin{tabular}{|c|c|c|c|c|c|c|c|c|c|c|c|c|c|c|}
\hline $\begin{array}{l}\text { LANTHANIDES } \\
\text { (RARE EARTHS) }\end{array}$ & La & $\mathrm{Ce}$ & $\mathrm{Pr}$ & $\mathrm{Nd}$ & $\mathrm{Pm}$ & $\mathrm{Sm}$ & $\mathrm{Eu}$ & $\mathrm{Gd}$ & $\mathrm{Tb}$ & $\mathrm{Dy}$ & $\mathrm{Ho}$ & $\mathrm{Er}$ & $\mathrm{Tm}$ & $\mathrm{Yb}$ \\
\hline
\end{tabular}

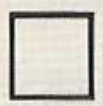

TRANSITION ELEMENT SUPERCONDUCTORS

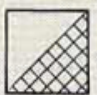

SUPERCONDUCTING (ONLY UNDER PRESSURE)

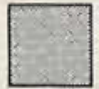

TRANSITION ELEMENT SUPERCONDUCTORS (ONLY UNDER PRESSURE)

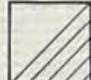

NON - TRANSITION ELEMENT SUPER-

NON - TRANSITION ELEMENT SUPER-
CONDUCTORS (ONLY UNDER PRESSURE)

NON - TRANSITION ELEMENT

SUPERCONDUCTORS

NOT SUPERCONDUCTING

Fig. 1 Distribution of the superconducting elements in the periodic system.

$$
\mathrm{T}_{\mathrm{r}} \alpha \theta_{D} \exp .-\left(\frac{1}{\mathrm{~N}(\mathrm{O}) \mathrm{V}}\right)
$$

Further modification by Eliashberg (3) and McMillan (4) gave the more refined equation for the superconducting transition temperature of:

$$
\mathrm{T}_{\mathrm{c}}=\frac{\theta_{D} \exp }{1.45}-\left(\frac{1.04(1+\lambda)}{\lambda-\mu^{*}(1+0.62 \lambda)}\right)
$$

Where $\lambda$ is the electron-phonon interaction constant and $\mu^{*}$ is the coulomb repulsion parameter. In weak coupling where $\lambda \ll 1$ this expression reduces to the BCS model with $N(O) V$ equal to $\lambda-\mu^{*}$. Thus superconductors are classified as weak or intermediate coupled $(\lambda<1)$, and strongly coupled $(\lambda>1)$.

As examples, the values of $\lambda$ for $\mathrm{V}_{3} \mathrm{Au}$ and $\mathrm{Nb}_{3} \mathrm{Au}$ alloys with A15 structure are 0.54 and 0.87 respectively (5).

Gold Bull., 1984, 17, (3)

\section{Superconducting Gold Compounds}

Compounds of gold with other elements which exhibit superconductivity have been described below in relation to the Periodic Table group in which the alloying element is found.

\section{Compounds with Group I and II Elements}

The compounds of gold with the elements of groups IA and IB do not become superconductors, typical examples being compounds like $\mathrm{Au}_{2} \mathrm{Na}, \mathrm{AuNa}_{2}, \mathrm{Au}_{5} \mathrm{~K}, \mathrm{AuCu}$ and $\mathrm{Cu}_{3} \mathrm{Au}$. However the compounds of gold with the elements of groups IIA and IIB do become superconductors with $\mathrm{T}_{\mathrm{c}}$ values ranging between 0.34 and $2.79 \mathrm{~K}$ as listed in Table $\mathrm{I}$.

Barium is superconducting only under pressure but an intermetallic compound with gold becomes superconducting at temperatures as high as $2.79 \mathrm{~K}$. The intermetallic compound of 


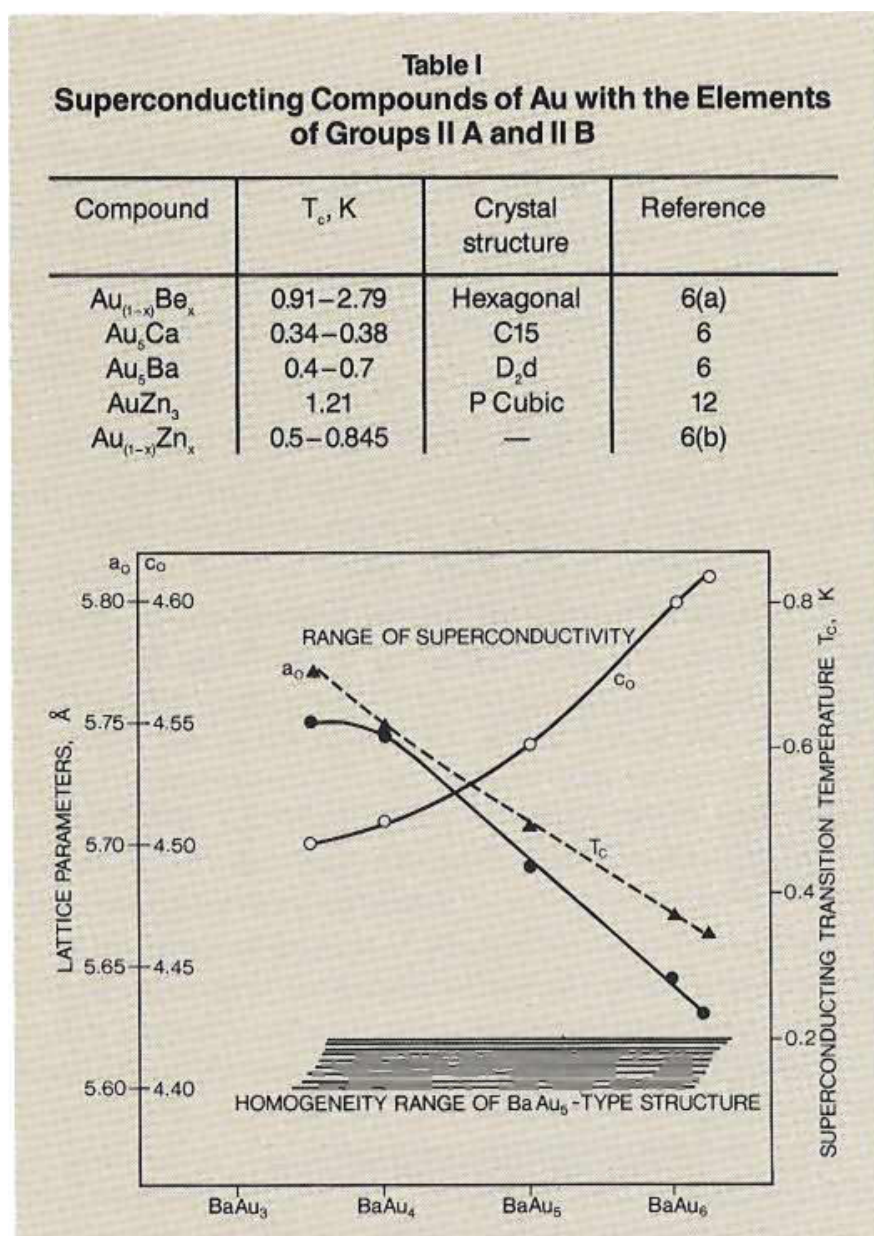

Fig. 2 Relationship between lattice parameters, composition and superconducting behaviour in the $\mathrm{BaAu}_{5}$-type structure

Table II

Superconducting Compounds of $\mathrm{Au}$ With the Elements of Groups III A and III B

\begin{tabular}{c|c|c|c}
\hline Compound & $T_{0}, \mathrm{~K}$ & $\begin{array}{c}\text { Crystal } \\
\text { structure }\end{array}$ & Reference \\
\hline AuGa & 1.2 & $\mathrm{~B} 31$ & 6 \\
$\mathrm{AuGa}_{2}$ & 0.34 & $\mathrm{C} 1$ & 7 \\
$\mathrm{Auln}_{2}$ & $0.096-0.093$ & - & 7 \\
$\mathrm{Auln}$ & $0.4-0.6$ & Complex & 6 \\
$\mathrm{AlAu}_{4}$ & $0.4-0.7$ & as A 13 & 6 \\
$\mathrm{AuTI}$ & 1.92 & - & 12
\end{tabular}

composition $\mathrm{Au}_{5} \mathrm{Ba}\left(D_{2} d\right.$ structure) exists in the homogeneity range of compositions $\mathrm{BaAu}_{3,5}$ to $\mathrm{BaAu}_{6,5}$. The variation of $\mathrm{T}_{\mathrm{c}}$ and lattice parameters with composition is shown in Figure 2, from which it can be seen that $T_{c}$ decreases with increasing gold concentration.

\section{Compounds with Group III Elements}

Table II shows the listing of the superconducting compounds of gold formed with the elements of IIIA and IIIB groups along with their crystal structures and $T_{c}$ values. The highest $T_{c}$ value is observed for the compound AuT1 $\left(\mathrm{T}_{\mathrm{c}}=1.92 \mathrm{~K}\right)$. Hamilton et. al. (6) reported on the existence of superconductivity in the goldgallium system. The compound AuGa becomes superconducting at $1.24 \mathrm{~K}$ whereas $\mathrm{AuGa}_{2}$ is not superconducting above $0.34 \mathrm{~K}$. Later Wernick et al. (7) reported that $\mathrm{AuGa}_{2}$ with a crystal structure of the $\mathrm{CaF}_{2}$-cubic type became superconducting at $1.1 \mathrm{~K}$. The discovery of superconductivity in $\mathrm{AuGa}_{2}$ and the ternary compound $\left(\mathrm{Au}_{(1-x)} \mathrm{Pd}_{\mathrm{x}}\right) \mathrm{Ga}_{2}(\mathrm{x}<0.15)$ led Schirber $(8)$ to predict and subsequently verify (9) that the parameter $\left(\delta T_{c} / \delta P\right)$ of $\mathrm{AuGa}_{2}$ shows a sharp increase for applied pressures between 5 and $6 \mathrm{kbar}$, that is to say $T_{c}$ increases from $1.3 \mathrm{~K}$ at $5 \mathrm{kbar}$ to $1.9 \mathrm{~K}$ at $6 \mathrm{kbar}$. The author and his colleagues investigated a number of binary and ternary compounds of gold, gallium and palladium of different compositions (10). The $T_{\mathrm{c}}$ values, as well as the gradient $\left(d H_{c} d d T\right)_{\text {Tr }}$ of the plot of the critical field versus temperature at the zero applied magnetic field are listed in Table III. The transition widths as well as the X-ray and metallographic data are also listed in the same table, and these indicate whether a compound is single phase or consists of two or more phases. $\mathrm{T}_{\mathrm{c}}$ as well as $\left(d \mathrm{H}_{c} / d T\right)_{\mathrm{Tc}}$ increases with the increase of gallium concentration in $\mathrm{Au}_{(1-x)} \mathrm{Ga}_{\times}$ compounds.

The temperature variation of the critical magnetic field of different samples is also shown in Figure 3 . The investigations from which these results are derived have shown that the superconductivity of the gold-gallium system is not as simple to understand as was thought earlier. The $\mathrm{T}_{c}$ values of the compound $\mathrm{AuGa}_{2}(\mathrm{Cl}$ structure) depend upon the metallurgical history of the sample. The homogeneity range of the $C 1$ structure lies between 67.2 to 71.9 gallium atomic per cent with $\mathrm{T}_{\mathrm{c}}$ values significantly higher than the reported values of $1.1 \mathrm{~K}$ for the single crystal samples. Hyot and Mota (11) studied the $T_{c}$ variation of vanadiumgallium dilute solid solutions and predicted that gold would become superconducting at a temperature lower than $0.2 \mathrm{mK}$.

\section{Compounds with Group IV Elements}

None of the transition metals titanium, zirconium and hafnium of group IVB form superconducting compounds with gold. Due to the stabilization of the b.c.c. $\beta$ phase, gold enhances the $T_{c}$ value of zirconium to a value of $2.8 \mathrm{~K}(12)$. Superconducting compounds of germanium (13), tin (14) and lead (15) are formed with gold, although there is a possibility that in the case of gold-tin and goldlead the presence of free tin or lead might have caused the superconductivity tather than the intermetallic compounds. A superconducting gold-germanium compound $\left(\mathrm{T}_{\mathrm{c}}=2.7 \mathrm{~K}\right)$ is formed only by rapid quenching, hence the structure and composition are not completely established. Compounds like AuSn and $\mathrm{AuSn}_{4}$ have hexagonal and primitive cubic structures, and 
Table III

The Superconducting, Chemical and Metallurgical Data for Ten Au-Ga Compound Samples and Three Pd-doped AuGa ${ }_{2}$ Samples

\begin{tabular}{|c|c|c|c|c|c|}
\hline Composition & Sample & $T_{c}$ & $\Delta \mathrm{T}$ & $\begin{array}{c}\left(\mathrm{dH}_{\mathrm{c}} / \mathrm{dT}\right)_{\mathrm{T}_{\mathrm{c}}} \\
\mathrm{Oe} / \mathrm{K}\end{array}$ & Remarks \\
\hline 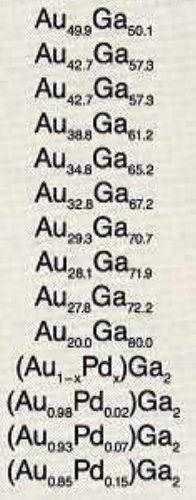 & $\begin{array}{c}1 \\
2 \\
4 \\
3 \\
8 \\
7 \\
5^{a} \\
6^{b} \\
9 \\
10 \\
- \\
- \\
-\end{array}$ & $\begin{array}{c}1.17 \\
1.378 \\
1.387 \\
1.355 \\
1.27 \\
1.668 \\
1.630 \\
1.587 \\
1.615 \\
1.587 \\
1.510 \\
1.773 \\
1.790\end{array}$ & $\begin{array}{l}0.23 \\
0.26 \\
0.12 \\
0.13 \\
0.13 \\
\\
0.02 \\
0.10\end{array}$ & $\begin{array}{l}-106 \\
-123 \\
-112 \\
-412 \\
-252 \\
-241 \\
-243 \\
-243\end{array}$ & $\begin{array}{l}\text { Single phase, homogeneous, } \mathrm{AuGa} \text {. B31 } \\
\text { Two phase, } \mathrm{AuGa}+\mathrm{AuGa}_{2} \\
\text { Two phase, } \mathrm{AuGa}+\mathrm{AuGa}_{2} \\
\text { Two phase, } \mathrm{AuGa}+\mathrm{AuGa}_{2} \\
\text { Two phase, } \mathrm{AuGa} \mathrm{Ga}_{2}+\mathrm{Ga} \\
\text { Single phase, homogeneous, } \mathrm{AuGa} \mathrm{G}_{2}=\mathrm{C1} \\
\text { Single phase, homogeneous, } \mathrm{AuGa} \mathrm{G}_{2}-\mathrm{C} 1 \\
\text { Single phase, homogeneous, } \mathrm{AuGa} \mathrm{a}_{2}-\mathrm{C} 1 \\
\text { Two phase, AuGa } \mathrm{Ga}_{2}+\mathrm{Ga} \\
\text { Two phase, AuGa }+\mathrm{Ga} \\
\text { Single phase, homogeneous } \\
\text { Single phase, homogeneous } \\
\text { Two phase }\end{array}$ \\
\hline
\end{tabular}

${ }^{a}$ By X-ray and metallographs

'Small ( $3 \%$ of total signal) transition at $\mathrm{T} \sim 1.40 \mathrm{~K},\left(\mathrm{dH}_{\mathrm{c}} / \mathrm{dT}\right)_{\mathrm{T}_{\mathrm{c}}} \sim 140 \mathrm{Oe} / \mathrm{K}$

their $T_{c}$ values are 2.0 and $3.0 \mathrm{~K}$, respectively.

\section{Compounds with Group V Elements}

Only antimony (15) and bismuth of group VA react to form superconducting compounds such as $\mathrm{Au}_{2} \mathrm{Sb}\left(\mathrm{T}_{\mathrm{c}}=0.58 \mathrm{~K}\right)$ and $A u_{2} \mathrm{Bi}\left(\mathrm{T}_{\mathrm{c}}=1.84 \mathrm{~K}\right)$, whereas $\mathrm{Au}_{2} \mathrm{P}_{3}$ is not superconducting above $10 \mathrm{mK}$.

\section{Other Transition Element Compounds of Gold}

Gold forms A15-phase compounds with the elements vanadium, niobium and tantalum which are superconducting. $\mathrm{Nb}_{3} \mathrm{Au}$ (A15-phase) has the highest $\mathrm{T}_{\mathrm{c}}$ value of $10.5 \mathrm{~K}(16)$ whereas $\mathrm{Ta}_{3} \mathrm{Au}$ has a $\mathrm{T}_{\mathrm{c}}$ value of $0.5 \mathrm{~K}(17)$. Addition of a third transition metal like thodium and platinum to $\mathrm{Nb}_{3} A u$ further raises the $\mathrm{T}_{\mathrm{c}}$ value. Thus the critical temperature of $\mathrm{Nb}_{3} \mathrm{Au}_{0.98} \mathrm{Rh}_{0.02}$ is $10.9 \mathrm{~K}(18)$ and that of $\mathrm{Nb}_{3} \mathrm{Au}_{0.7} \mathrm{Pt}_{0.3}$ has a value of $12.8 \mathrm{~K}(16)$. The superconducting as well as the electronic properties of $\mathrm{Nb}_{3} \mathrm{Au}_{(1-\mathrm{x})} \mathrm{Pt}_{\mathrm{x}}$ are dependent on the annealing conditions, which affect the long range atomic order parameter. For example $\mathrm{Nb}_{3} \mathrm{Au}_{0.7} \mathrm{P}_{\mathrm{t}_{0.3}}$, in as-cast condition, has a $\mathrm{T}_{\mathrm{c}}$ value of $9.3 \mathrm{~K}$ whereas the same sample after a heat treatment of $4 \mathrm{~h} / 1450^{\circ} \mathrm{C}+7 \mathrm{~d} / 750^{\circ} \mathrm{C}$ achieves an increased $\mathrm{T}_{c}$ value of $12.45 \mathrm{~K}$ as shown in Table IV (19). The critical magnetic fields of compositions within this system are shown as a function of temperature in Figure 4. A systematic variation of $T_{c}$ with composition in the ternary $\mathrm{Nb}_{3} \mathrm{Au}-\mathrm{Nb}_{3} \mathrm{Pt}$ system is shown for both the as-cast and annealed conditions in Figure 5 (20).

$\mathrm{V}_{3} \mathrm{Au}$ possesses the $A 15$-structure and has the same electron
Fig 3 Dependence of critical magnetic fields on temperature for selected Au-Ga samples

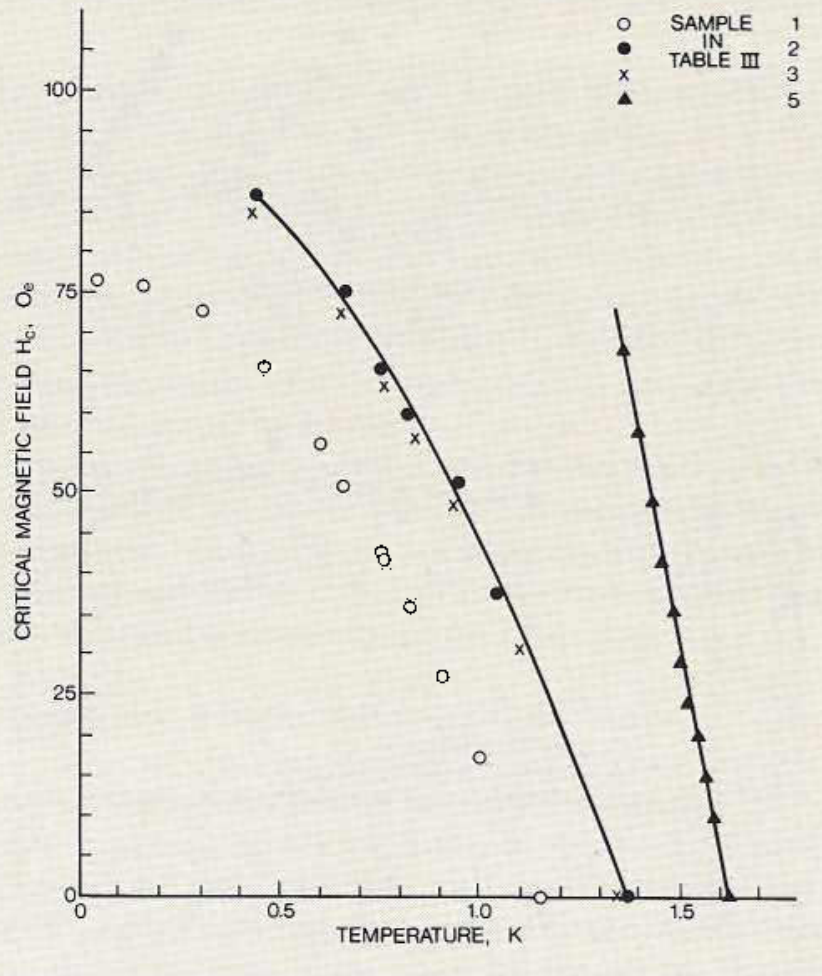


Fig. 4 (Top) Upper critical magnetic field as a function of temperature for the pseudobinary system $\mathrm{Nb}_{3} \mathrm{Au}_{x} \mathrm{Pt}_{1-x}$. The inverted triangle point represents the pulsed field data point for $\mathrm{Nb}_{3} \mathrm{Au}_{0.7}, \mathrm{Pt}_{0.3}$. The solid circles are from a $\mathrm{Nb}_{3} \mathrm{Au}_{0,7} \mathrm{Pt}_{0,3}$ sample heated to $1250^{\circ} \mathrm{C}$ then water quenched, and the cross points are from a $\mathrm{Nb}_{3} \mathrm{Pt}$ sample annealed at $950^{\circ} \mathrm{C}$ for 1 month

Fig. 5 (Bottom) Variation of the superconducting transition temperature of $\mathrm{Nb}_{3} \mathrm{Pt}_{(1-x)} \mathrm{Au}_{\mathrm{x}}$ alloys in the as-cast and annealed states as a function of the fraction of $\mathrm{Nb}_{3} \mathrm{Pt}$ (mol.\%)
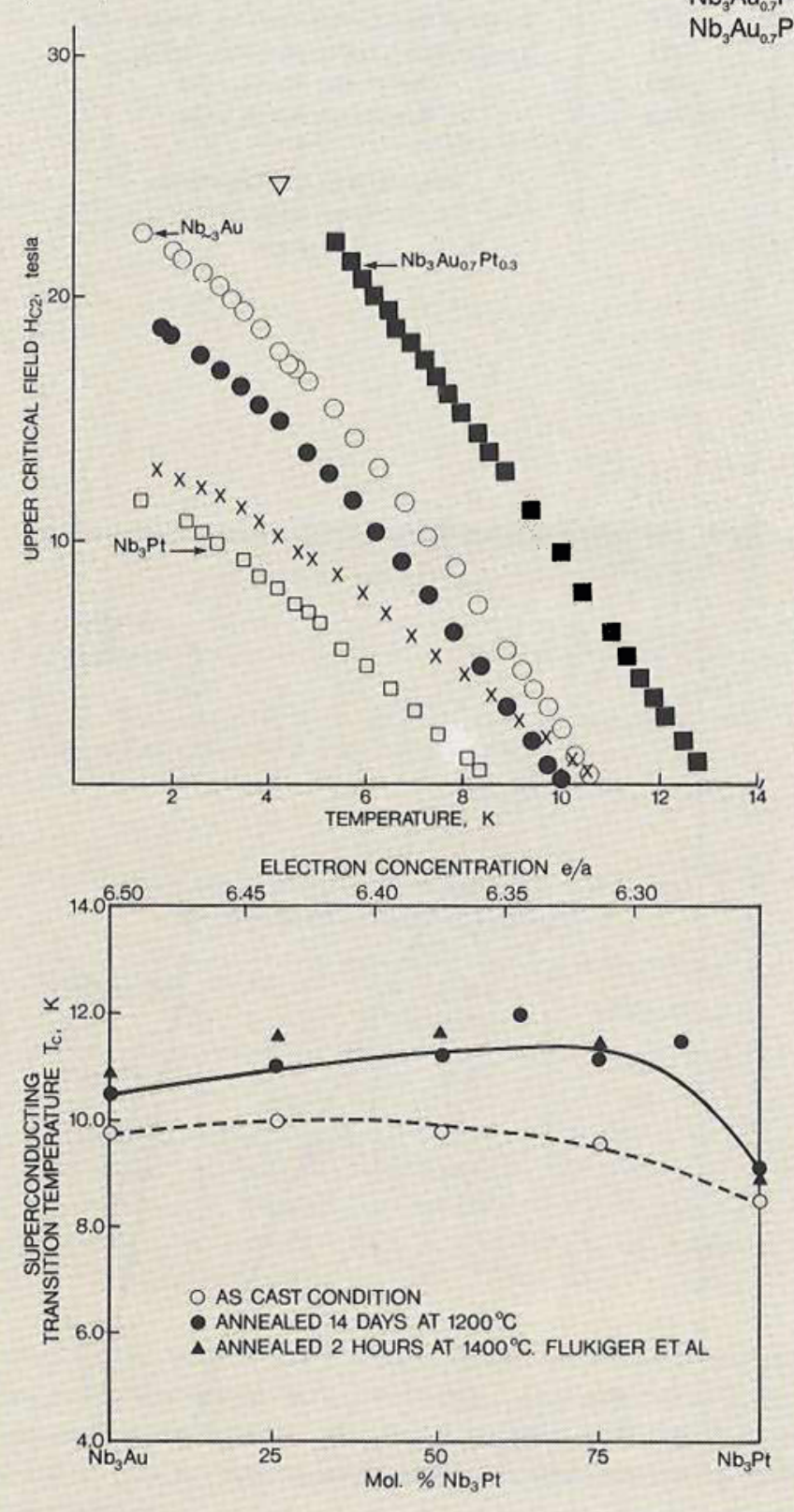

Table IV

Lattice Constant, Superconducting Transition Temperature $\left(\mathrm{T}_{\mathrm{c}}\right)$, and Electronic Specific Heat $(\gamma)$ for $\mathrm{Nb}_{-3} \mathrm{Au}, \mathrm{Nb}_{3} \mathrm{Au}_{0.7} \mathrm{Pt}_{0.3}$ and $\mathrm{Nb}_{3} \mathrm{Pt}$ after Different Annealing Treatments

\begin{tabular}{|c|c|c|c|c|c|}
\hline Compound & $\begin{array}{l}\text { Heat } \\
\text { treatment, } \\
{ }^{\circ} \mathrm{C}\end{array}$ & $\begin{array}{c}\text { Lattice } \\
\text { constant } a \text {, } \\
\AA\end{array}$ & $\begin{array}{l}T_{0}, \\
K\end{array}$ & $\begin{array}{c}\gamma, \\
\mathrm{mJ} / \mathrm{K}^{2} \text { at-g }\end{array}$ & Reference \\
\hline $\mathrm{Nb}_{3} \mathrm{Pt}$ & $10 \mathrm{~h} / 1450$ & 5.155 & 8.9 & 5.55 & $14(a)$ \\
\hline $\mathrm{Nb}_{3} \mathrm{Pt}$ & $\begin{array}{r}10 \mathrm{~h} / 1450 \\
+7 \mathrm{~d} / 900\end{array}$ & 5.155 & 10.6 & 5.9 & 14(a) \\
\hline $\mathrm{Nb}_{-3} \mathrm{Au}$ & $20 \mathrm{~h} / 1050$ & 5.202 & 10.9 & 9.3 & $14(b)$ \\
\hline $\mathrm{Nb}_{3} \mathrm{Au}_{0,7} \mathrm{Pt}_{03}$ & as-cast & 5.196 & 9.3 & 5.8 & 11 \\
\hline $\mathrm{Nb}_{3} \mathrm{Au}_{0,7} \mathrm{Pt}_{03}$ & $10 \mathrm{~h} / 1450$ & 5.196 & 12.45 & 8.54 & 14(a) \\
\hline
\end{tabular}

concentration as $\mathrm{Nb}_{3} \mathrm{Au}$ but a critical temperature value of only $0.74 \mathrm{~K}$. A low temperature annealing raises the $\mathrm{T}_{\mathrm{c}}$ value to $2.8 \mathrm{~K}$ due to an increase of the order parameter which subsequently raises the electron density of states and hence $T_{c}(21)$. Recently Jarlbord et al. (22) have derived the $\mathrm{T}_{\mathrm{c}}$ value of this compound from the electronic structure data. The calculated value of $T_{c}$ is around 10.2 K. Such a big difference between the experimental and calculated values of $\mathrm{T}_{\mathrm{c}}$ suggests the presence of spin fluctuations, the presence of which would bring a compound closer to a ferromagnetic regime. In any event $\mathrm{V}_{3} \mathrm{Au}$ is a good candidate for the study of the physics of spin fluctuations since the compound has an observable $T_{c}$ value. A similar effect was observed in the case of the solid solutions of vanadium with the $3 d, 4 d$ and $5 d$ transition metals. It was found that in the solid solutions of the series, $\mathrm{V}_{0.00} \mathrm{X}_{0.10}(\mathrm{X}=\mathrm{Cr}, \mathrm{Mn}, \mathrm{Nb}$, Mo, Pd, Ta, W, Re, Ptand Au), the lowest critical temperature value of $0.30 \mathrm{~K}$ is observed for the composition $\mathrm{V}_{0.90} \mathrm{Au}_{0.10}$ (23) (Figure 6) whereas the calculated value from the electronic structure is $0.9 \mathrm{~K}$ (24). The experimental and calculated values of $\mathrm{T}_{c}$ differ by a factor of 3, similar to the compound $\mathrm{V}_{3} \mathrm{Au}$, which also suggests the presence of spin fluctuations in the $\mathrm{V}_{0.90} \mathrm{Au}_{0.10}$ solid solution. In addition to this it should be noted that $\mathrm{Au}_{4} \mathrm{~V}$ has the interesting property of being one of the few ferromagnets with no fertomagnetic constituent elements.

Among the group VIA elements, only the gold-tellurium compound $\mathrm{Au}_{3} \mathrm{Te}_{\text {, }}$ is superconducting (25) and none of the gold compounds with the elements of groups VIB and VIIIB are superconductors. Some other superconductors worth mentioning are AuLa $\left(\mathrm{T}_{c}=0.35 \mathrm{~K}\right)(26)$ and the pseudobinary carbide $\mathrm{AuC}_{13} \mathrm{Y}_{09}\left(\mathrm{~T}_{\mathrm{c}}=10.1 \mathrm{~K}\right)(27)$.

Gold forms a low temperature eutectic with lanthanum and this low eutectic condition was pointed out as a favourable condition for obtaining an amorphous alloy by liquid quenching (28). In 1975 an amorphous superconducting alloy was obtained by rapid quenching from the liquid state (29), which had the composition of $\mathrm{La}_{80} \mathrm{Au}_{20}$. The critical temperature value of this metallic glass is $3.5 \mathrm{~K}$ and decreases with an increase in gold concentration, for example the $T_{c}$ value of $\mathrm{La}_{76} \mathrm{Au}_{24}$ is $3.3 \mathrm{~K}$. Since then many metallic 


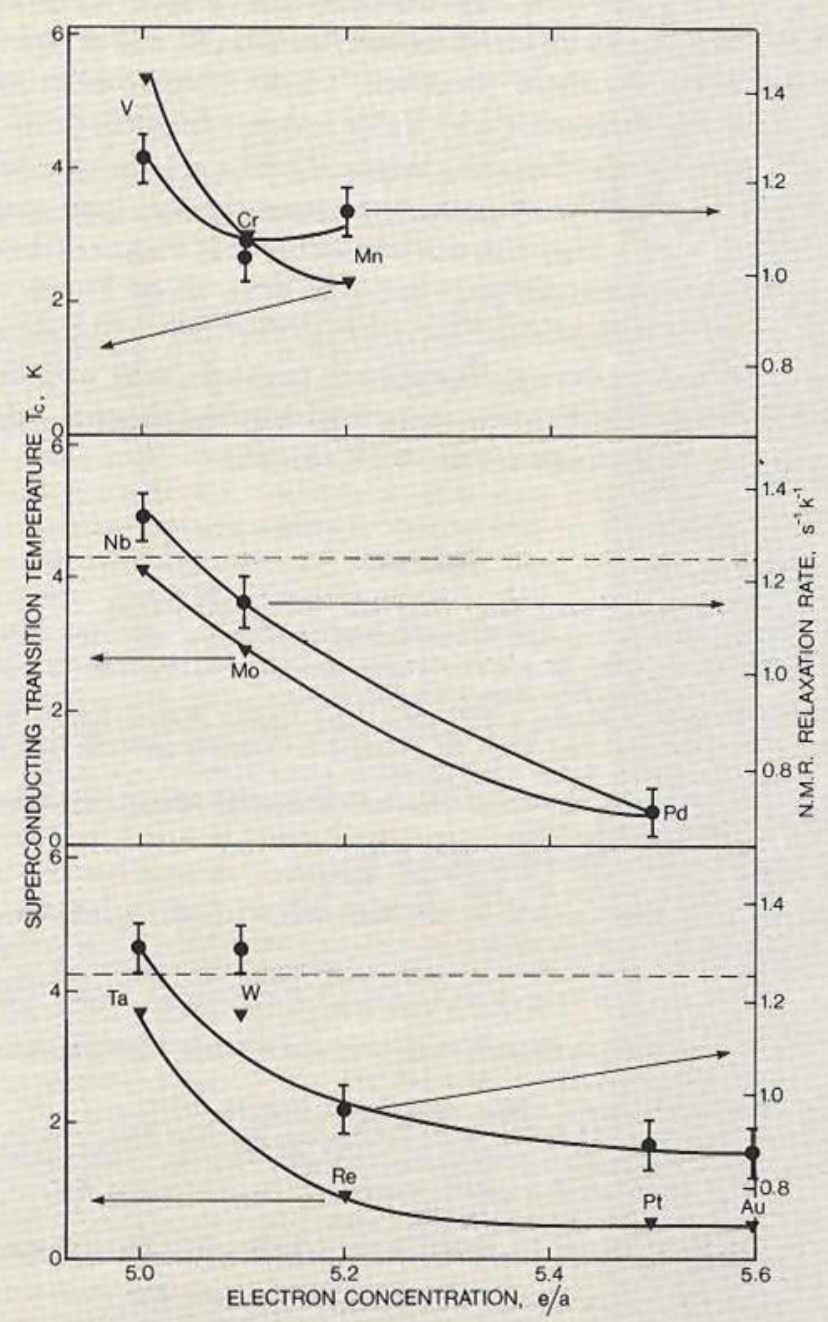

Fig. 6 Variation of electrical resistivity and NMR relaxation rates of $\mathrm{V}_{0.9} \mathrm{Au}_{0.1}$ and other binary vanadium alloys of the same composition as a function of electron concentration e/a

glass superconductors based on transition metals and metalloids have been discovered. These metallic glass superconductors have potential applications due to good mechanical properties, high magnetic field and critical current in the pseudoamorphous state, as well as resistance to neutron radiation damage.

\section{Epitaxial Metal Film Sandwiches (EMFS)}

Recent work by Brodsky and his colleagues $(30 \mathrm{a}, 30 \mathrm{~b})$ has shown that by epitaxial growth of thin films of metal on layers of gold to form Au-M-Au sandwich structures, a new class of materials can be produced in which novel electronic and magnetic properties are evident. Among these is enhanced superconductivity which occurs particularly in the Au-Cr-Au system. The highest measured $\mathrm{T}_{\mathrm{c}}$ for this material was $3.0 \mathrm{~K}$ which is thought to occur from the formation

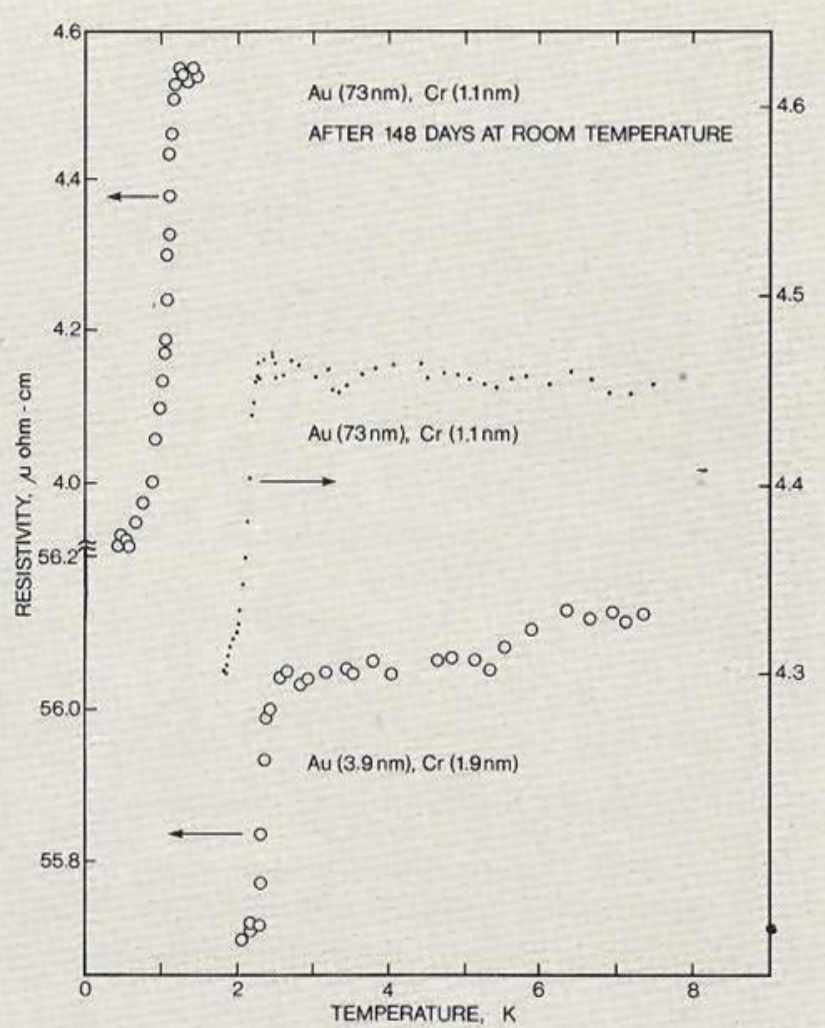

Fig. 7 Resistivity of different Au-Cr-Au epitaxial metal film sandwich samples as a function of temperature

of metastable fcc chromium on the fcc gold. Measurements of ${ }^{\prime}{ }_{c}$ for sputtered bcc chromium have yielded a maximum value of only $1.52 \mathrm{~K}$. Figure 7 shows the resistivity of two $\mathrm{Au}-\mathrm{Cr}-\mathrm{Au}$ composites as a function of temperature, and in Figure 8 the relationship between critical magnetic field and critical temperature is shown for a sample of $\mathrm{Au}-\mathrm{Cr}-\mathrm{Au}$ in which the gold layers are $73 \mathrm{~nm}$ and the chromium film $1.1 \mathrm{~nm}$ thick. The latter figure shows the effect of applying the magnetic field both perpendicular and parallel to the plane of the metal film sandwich.

Such materials are thought to have possible applications in a number of electronic devices, although further research is required in some areas, in particular an observed tendency for the enhanced superconductivity effect of the EMFS to decrease when the sample has been standing at room temperature for a time.

\section{Applications of Superconducting Gold Alloys}

Some superconducting alloys of gold find applications as reference temperature material below $0.5 \mathrm{~K}$. For example AuIn is superconducting at $0.204 \mathrm{~K}$ and has a good reproducibility between 0.1 and $0.4 \mathrm{mK}$ (31). Figure 9 shows a fixed point superconductive device based on $\mathrm{AuIn}_{2}$ and $\mathrm{AuAl}_{2}$ as two of the five materials which provide the reference temperatures for the device. The other 


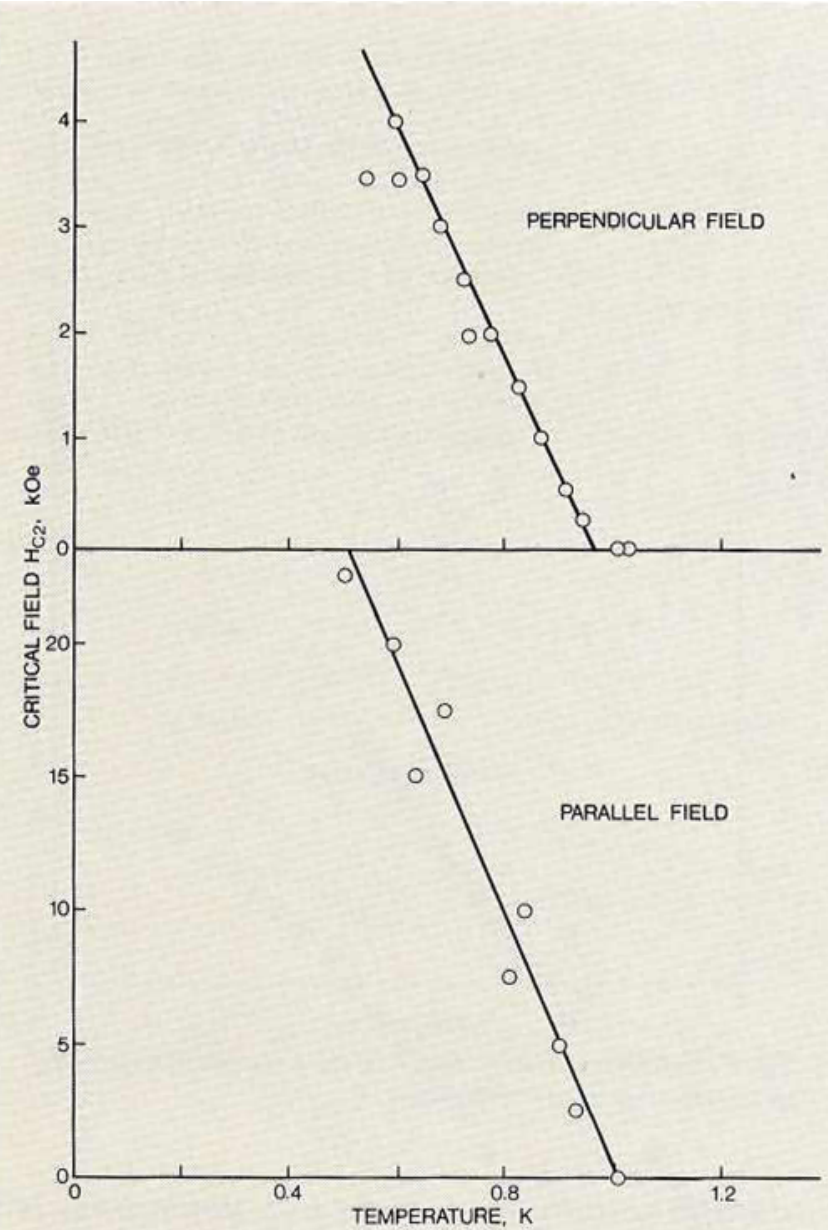

Fig. 8 Critical magnetic field as a function of critical temperature for a Au-Cr-Au metal film sandwich where the thicknesses of the gold and chromium layers are 73 and $1.1 \mathrm{~nm}$ respectively. The upper plot represents the application of the magneticfield in the plane perpendicular to that of the sandwich, and the lower plot is derived from a parallel magnetic field.

Fig. 9 Fixed point device for providing five reference temperatures below $0.5 \mathrm{~K}$ with excellent reproducibility. Samples of $\mathrm{AuAl}_{2}, \mathrm{AuIn}_{2}$, W, Be and Ir are bundled in copper wires which also enclose 2 sets of coils (primary and secondary). The whole assembly is electroplated with pure gold to a thickness of approximately $0.5 \mu \mathrm{m}$

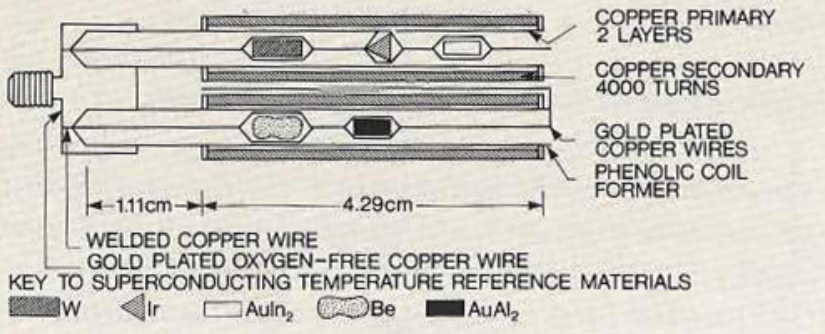

applications of gold-based superconducting alloys are in Josephson tunnel junctions for logic and memory circuits $(32,33)$. A type of device based on these junctions, SQUID (Superconducting Quantum Interference Device), is able to detect magnetic fields of about 10 femtotesla (the earth's magnetic field is $\sim 60$ microtesla). There is a possibility of producing extremely fast, large scale integrated circuit chips with this technology (34). Failure of these Josephson junctions takes place due to thermal cycling. The use of lead-gold and lead-gold-indium alloys as electrodes and counter electrodes in these devices has improved the workability, and they have been reported to withstand several hundred thermal cycles between room temperature and $4.2 \mathrm{~K}(35,36)$.

\section{References}

H.R. Khan and Ch. J. Raub, Gold Bull., 1975, 8, (4), 114-118

J. Bardeen, L.N. Cooper and J.R. Schrieffer, Phys, Rev, 1957, 108, 1175

G.M. Eliashberg, Zh. eksper. teor. Fiz., 1960, 38, 966 and 1960, 39, 1437

W.L. McMillan, Phys. Rev., 1968, 167, 331

F. Heiniger, E. Bucher and J. Müller, Phys. Kodens. Materie, 1966, 5, 243 D.C. Hamilton, Ch.J. Raub, B.T. Matthias, E. Corenzwit and G.W. Hull, Jr., J. Phys. Chem. Solids, 1965, 26, 665

J.H. Wernick, A. Menth, T.H. Geballe, G. Hull and J.P. Maita, J.Phys. Chem. Solids, 1969, 30, 1949

J.E. Schirber, Phys. Rev. B, 1972, 6, 333
J.E. Schitber, Phys. Rev. Lett., 1972, 28, 1127

R.A. Hein, J.E. Cox, J. Wills, H.R. Khan and Ch.J. Raub, J. Less-Common Metals, 1978, 62, 197-209

11 R.F. Hoyt and A.C. Mota, Solid State Commun., 1976, 18, 139

12 B.W. Roberts, in 'Progress in Cryogenics, Vol. 4', Heywood, London, 1964 p. 160

13 B. Stritzker and H. Wuhl, Z. Phys, 1971, 243; H.L. Luo, M.F. Merriam and D.C. Hamilton, Science, 1964, 145, 581

E. Klokholm and C. Chion, Acta Metall., 1966, 14, 565

B.T. Matthias, T.H. Geballe and V.B. Compton, Rev. Mod. Physs, 1963, 35, 1 P. Spitzli, R. Flükiger, F. Heiniger and J. Müller, Phys. Lett., 1969, 30A, 170 H.L. Luo, E. Vielhaber and E. Corenzwit, Zn Phys., 1970, 230, 443

S.T. Zegler, Phys. Rev., 1965, 137A, 1438

R. Flükiger, S. Foner, E.J. McNiff, Jr. and E. Fischer, Solid State Commun., 1979, 30, 723-726

20 H.R. Khan, E. Röschel and Ch.J. Raub, Z. Pbys., 1973, 262, 279

21 E.C. van Reuth, R.M. Watetstraat, R.D. Blaugher, R.A. Hein and J.E. Cox, in 'Proc. 10th Internat. Conf. Low Temp. Phys. Vol. UI B', p. 137; E.C. van Reuth and R.M. Waterstraat, Acta Crystallogr, 1968, 24, 187; R.A. Hein, J.E. Cox, R.D. Blaugher, R.M. Waterstraat and E.C. van Reuth, Physica, 1971, 55, 523 T. Jarlborg, A. Junod and M. Peter, Phys. Rev. B, 1983, 27, (3), 1558-1567 H.R. Khan, Ch.J. Raub, W. Däumer, J. Goebbels, K. Lüders and G. Roth in 'Superconductivity in d-and f-band Metals', edited by W. Buckel and W. Werner, Kernforschungszentrum Karlsruhe, 1982, p. 381

F. Brouers, H.R. Khan and J. Van der Rest, ibid., p. 385

BW. Roberts, in 'Progress in Cryogenics. Vol. 4', Heywood, London, 1964 p. 160

26 T.F. Smith and H.L. Luo, J. Phys. Chem. Solids, 1967, 28, 569

27 M.C. Krupka, A.L. Giorgi, N.H. Krikorian and E.G. Szklarz, J. Less-Common Metals, 1969, 19, 113

28 M.H. Cohen and D. Turnbull Nature (London), 1961, 189, 131

29 W.L. Johnson, S.J. Poon and P. Duwez, Phys. Rev. B, 1975, 11, 150

30(a) M.B. Brodsky, J. Appl. Phys., 1981, 52, (3, Pt.2), 1665-1669

30(b) M.B. Brodsky, D. Marikar, R.J. Friddle, L. Singer and C.H. Sowers, Solid State Commun., 1982, 42, (9), 675-678

31 R.J. Soulen, Jr., Journal de Physique, Colloque C6, Supplement No. 8, Vol 39. August, 1978, p. C6-1166

32 J.H. Greiner, S. Basavaiah, and I.J. Ames, J. Vac. Sci. Technol, 1974, 11, 81

33 D.J. Herrell, I.E.E.E. J. Solid'State Circuits, 1975, SC-10, 360; H.H. Zappe IE E.E J Solid State Circuits, 1975, SC-10, 12

34 W. Anacker et al., 'Josephson Computer Technology', IBMJ.Res, Develop., 1980, 24, 107-264

35 S. Basavaiah and J.H. Greiner, J. Appl. Phys, 1977, 48, 4630

36 M. Murakamı. H.C.W. Huang and C.J. Kircher, J. Appl. Phys., 1983, 54, 743 